\title{
Systematic review of the efficacy of statins for the treatment of Alzheimer's disease
}

\author{
Authors: Marta Mejías-Trueba, ${ }^{A}$ María Antonia Pérez-Moreno ${ }^{B}$ and María Ángeles Fernández-Arche
}

\begin{abstract}
Alzheimer's disease (AD) is the most common type of dementia. Recent studies have assessed the possibility of using statins as treatment for AD. However, their efficacy is not clear. In this study, we collected the most relevant information about the efficacy of statins for the treatment of $A D$. We conducted a systematic literature search using MEDLINE, EMBASE and The Cochrane Library. We included clinical trials, meta-analyses and systematic reviews that analysed the efficacy of statins in AD. We also extracted the characteristics and efficacy results of the studies selected. Of the 304 articles identified, 13 complied with the inclusion criteria. The scientific quality of studies was high and their results indicated that there were no significant differences in the main efficacy variables between statins and placebo treatment for AD. Therefore, according to the available scientific evidence, statins have not shown an improvement in cognition and do not appear to offer significant benefits to patients with $A D$.
\end{abstract}

KEYWORDS: Alzheimer's disease, statins, efficacy, systematic review

\section{Introduction}

Alzheimer's disease (AD) is the most common type of dementia. It is a neurodegenerative pathology, whose incidence has increased in the past few years. With an estimated prevalence of 46.8 million cases worldwide in 2015, the number of patients with AD is expected to continue to increase in the coming years. ${ }^{1}$

There are two main manifestations of $A D$ : early-onset $A D$, which especially affects young people, and late-onset $A D$, which is more common and occurs mainly in older people, usually patients over 65 years old; therefore, ageing is considered to be the main risk factor for the disease. ${ }^{2}$

Pathologically, AD is associated with pronounced brain atrophy and an excessive amount of neuritic plaques, which contain neurofibrillary tangles comprising highly phosphorylated tau

Authors: ${ }^{\text {A }}$ hospital pharmacist, Pharmacy Department, University

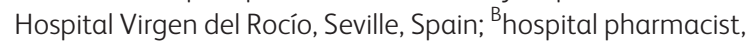
Pharmacy Department, University Hospital Virgen del Rocío, Seville, Spain; ' professor of pharmacology, Department of Pharmacology, Faculty of Pharmacy, University of Seville, Seville, Spain protein and extracellular deposits of $\beta$-amyloid $(A \beta) .{ }^{3}$ When these deposits accumulate in the cerebral cortex, they cause neurotoxic effects.

$A \beta$ peptides derive from the amyloid precursor protein (APP) in response to the activity of secretases ( $\alpha$-SAPP, $\beta$-SAPP and $\gamma$-SAPP), which cleave the APP into different fragments. ${ }^{4}$ These secretases have been the subject of scientific research because of their role in the regulation of $A \beta .^{5}$

$A \beta$ deposits contain apolipoprotein $E$ (apoE), a peptide found in the chylomicron, and very low-density lipoprotein (VLDL), which travels through the plasma transporting cholesterol to its receptors. In addition, apoE promotes the conversion of $A \beta$ into its insoluble form, generating neuritic plaques in patients with $A D$. Hence, the appearance of plaques should be directly proportional to the levels of apoE in the central nervous system. ${ }^{6}$ Therefore, polymorphism of the gene encoding apoE could indicate a risk of developing late-onset $A D$, given that apoE4 is associated with higher LDL cholesterol levels, which are involved in the accumulation of $A \beta$. $^{7}$

Currently, there is no effective curative treatment for $A D$ and the management of the disease is aimed at improving its symptoms. Drugs such as cholinesterase inhibitors (galantamine or rivastigmine) manage to slow the progression of the disease, but are only useful during the early stages of the disease. Memantine, a N-methyl-D-aspartic (NMDA) receptor antagonist, is effective during the advanced stages of the disease, protecting nerve cells in the brain from glutamate, a neurotransmitter that is released in excessive amounts in $\mathrm{AD} .^{8}$

Statins are hydroxymethylglutaryl coenzyme A reductase inhibitors that reduce cholesterol synthesis and increase the number of LDL receptors in hepatocyte membranes, enabling greater clearance of LDL from the bloodstream and lowering the level of lipoproteins. ${ }^{9}$ These are the drugs of choice for the treatment of hypercholesterolemia.

According to previous studies, patients treated with statins have a lower risk of developing $A D .^{10,11}$ In addition, some experimental studies have shown that statins treatment delays the progression of $A D$ because they reduce the production of $A \beta$ and, therefore, the decrease in cholesterol levels appears to inhibit the formation of the same. ${ }^{6,12}$

However, the efficacy of such drugs is not clear, given that the results of the latest clinical trials did not reflect an improvement on the parameters that are used to measure the cognitive impairment of patients. Nevertheless, some clinical guidelines for the treatment of $A D$ consider the use of statins as a possible 
treatment option for this pathology and some studies suggest its efficacy as treatment for certain subpopulations with AD. 13,14

Given the above, and because of the high prevalence of $A D$ and high frequency of publications respect to the use of statins in patients with $A D$, it would be necessary to perform a systematic assessment of its efficacy to identify possible subpopulations of patients who could benefit most from statin therapy.

For the above-mentioned reasons, the main objective of this review was to compile the most relevant information about the efficacy of the use of statins for the treatment of patients with AD.

\section{Methods}

\section{Selection criteria}

In concordance with the Preferred Reporting Items for Systematic Reviews and Meta-Analysis (PRISMA) guidelines, ${ }^{15}$ we conducted a systematic search of the literature published between January 2010 and April 2016 in the main biomedical databases MEDLINE (PubMed), EMBASE and The Cochrane Library. The search strategy is detailed as supplementary material.

We complemented our literature search by consulting different websites of drug regulatory agencies and scientific societies, and looking for new references within the documents found.

We included clinical trials, meta-analyses and systematic reviews that determined the efficacy of statins in $A D$, using parameters associated with the cause or the evaluation of the pathology, in patients diagnosed with $\mathrm{AD}$ and aged 18 or older.

Articles based on a different study design, those that evaluated the efficacy of the use of statins for the prevention of $A D$, and those written in languages other than English or Spanish were excluded.

\section{Study selection and quality assessment}

In a first phase, duplicates were eliminated. Then, eligible articles were selected based on information obtained from the title, abstract or full text, if necessary.

To ensure reproducibility and minimise bias, discrepancies were resolved by a second researcher. Subsequently, a critical reading of the selected articles was performed.

To assess the quality and validity of the clinical trials, we used the Spanish version of the Critical Appraisal Skills Programme (CASP) scale: the CASPe scale. ${ }^{16}$ The quality of the studies was scored on a $0-6$ scale, where 0 = negative or doubtful (no explicit information) and $>1=$ positive response; more specifically: $<3$ = low quality, 3 = medium-low quality, 4 = medium quality, $5=$ medium-high quality, $6=$ high quality. We used the AMSTAR tool to assess the quality of systematic reviews and meta-analyses. ${ }^{17}$ The score percentage was divided by 10 instead of 11 if the systematic review was rated as 'not applicable' on item 10, related to publication bias. The AMSTAR score percentage was used to classify the methodological quality of the study. A percentage of 0-33\% was classified as low quality; $34-66 \%$, as medium quality; and $67-100 \%$, as high quality.

\section{Data extraction and outcomes}

A descriptive analysis of the main characteristics of the studies selected was captured in an ad hoc table, considering the following variables: study design, number of patients included, selection criteria, characteristics of pathology and treatment regimens evaluated.

The following efficacy variables were considered:

> Mini-Mental State Examination (MMSE) score

$>$ AD Assessment Scale - Cognitive Portion (ADAS-Cog) score

$>$ Change in Neuropsychiatric Inventory (NPI) total score

> AD Cooperative Study - Clinical Global Impression of Change (ADCS-CGIC) score

> Analytical variables indicating AD: levels of $A \beta 40$ and $A \beta 42$ in plasma and in cerebrospinal fluid (CSF), total tau protein and phosphorylated tau protein levels, soluble amyloid precursor protein-beta (sAPP-b), soluble amyloid precursor protein-alpha (SAPP-a) and plasma levels of 24S-hydroxycholesterol.

\section{Statistical analysis}

The statistical analysis was carried out using Microsoft Excel 2007® and IBM SPSS Statistics $21 \circledR$. Qualitative variables were represented as percentages and quantitative variables were represented by measures of central tendency (mean) and measures of dispersion (standard deviation and range).

\section{Results}

\section{Literature search}

We identified a total of 304 articles within the databases consulted (52 in PubMed-MEDLINE, 218 in EMBASE, and 34 in the Cochrane Library).

Finally, 13 articles passed through the selection process: six clinical trials, six meta-analyses and one systematic review. Figure 1 shows the flowchart of the selection process for the systematic review.

The main reasons for excluding studies were: the study focused on the use of statins for the prevention of $\operatorname{AD}(48 \%)$; the study design was different from that required ( $41 \%)$; and the study analysed different variables from those considered ( $8 \%)$.

\section{Study characteristics}

Table 1 shows the quality score of each study, according to the CASPe scale and the AMSTAR tool. Generally, all the studies included were of high quality, with the exception of those conducted by Sjogren et $a l^{19}$ and Serrano-Pozo et a ${ }^{21}$ because of their non-randomised open-label design. All the meta-analyses were of high scientific quality and three of them obtained the maximum score on the AMSTAR scale. ${ }^{24,25,28}$

Tables 2 and 3 show the characteristics and the efficacy outcomes of the clinical trials and meta-analyses selected, respectively. In general, the study populations comprised older patients diagnosed with mild-moderate AD and MMSE scores between 12 and 26 , in most cases.

The systematic review performed by Xiong et al included a total of nine randomised, crossover and placebo-controlled clinical trials that studied the cognitive effects of statins. ${ }^{29}$

\section{Clinical outcomes}

Simons et al did not find any significant differences in ADAS-Cog score between patients treated with simvastatin and those treated with placebo. ${ }^{18}$ However, they found significant differences between both groups in terms of the MMSE score. Differences in the variation 


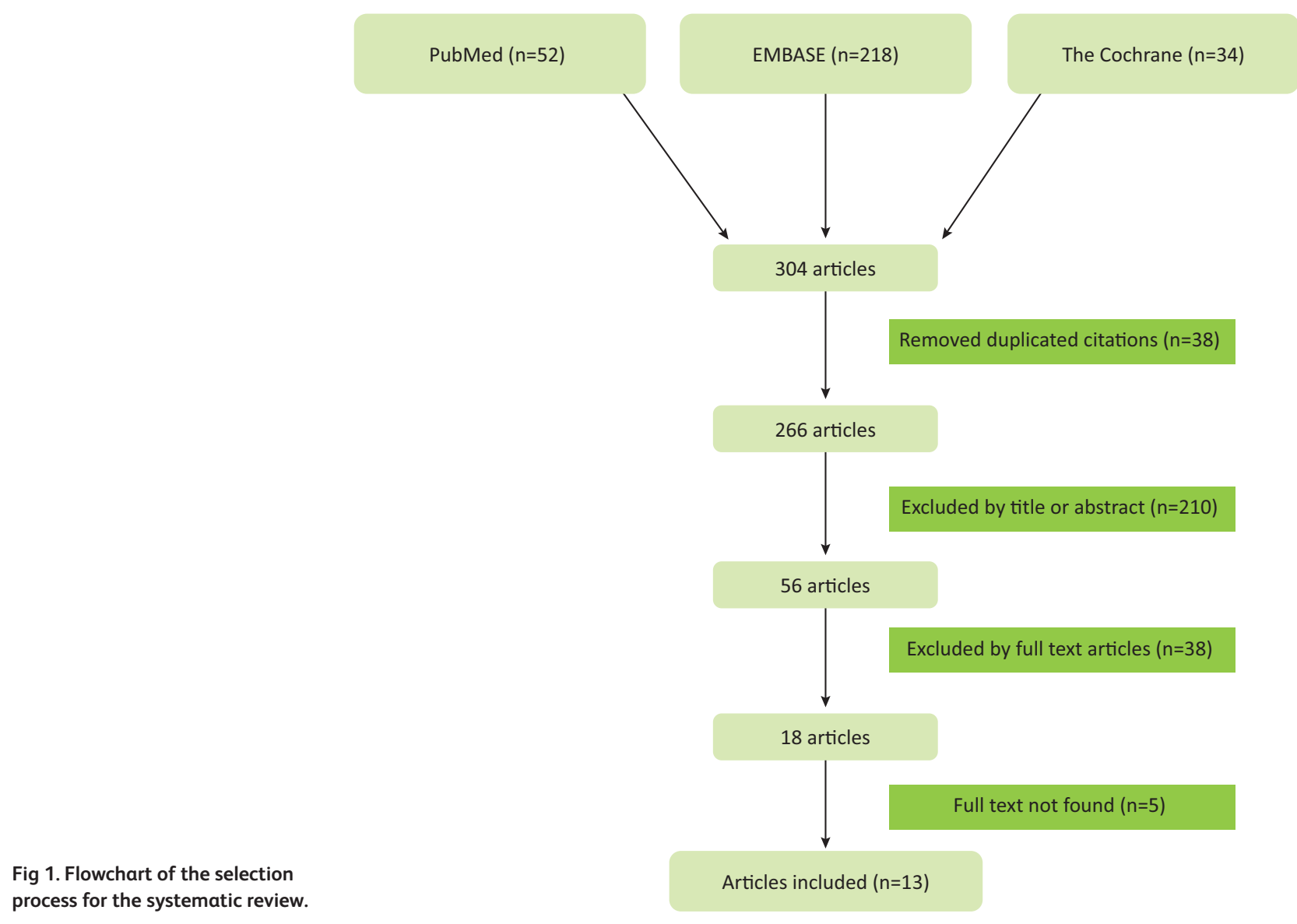

of $A \beta 40$ and 245 -hydroxycholesterol levels in favour of simvastatin were detected in patients with MMSE scores between 20 and 26.

Sparks et al observed results that favoured atorvastatin against placebo, according to ADAS-Cog, MMSE and CGIC scores. ${ }^{20}$

\section{Table 1. The quality and CASPe/AMSTAR scores of}

the studies examined

\begin{tabular}{|c|c|c|c|}
\hline Study & CASPe $^{16}$ & AMSTAR tool ${ }^{17}$ & Study quality \\
\hline Sano et al ${ }^{7}$ & $6 / 6$ & & High \\
\hline Simons et al ${ }^{18}$ & $6 / 6$ & & High \\
\hline Sjogren et $a l^{19}$ & $3 / 6$ & & Medium-low \\
\hline Sparks et al ${ }^{20}$ & $6 / 6$ & & High \\
\hline Serrano et $a l^{21}$ & $3 / 6$ & & Medium-low \\
\hline Feldman et $a 1^{22}$ & $6 / 6$ & & High \\
\hline Zhou et $a l^{23}$ & & $9 / 11$ & High \\
\hline Gizachew et al ${ }^{24}$ & & $11 / 11$ & High \\
\hline Sun et $a l^{25}$ & & $11 / 11$ & High \\
\hline Pandey et $a 1^{26}$ & & $9 / 11$ & High \\
\hline Richardson et $a^{27}$ & & $9 / 11$ & High \\
\hline McGuiness et al ${ }^{28}$ & & $11 / 11$ & High \\
\hline Xiong et $a^{29}$ & & $7 / 10^{a}$ & High \\
\hline
\end{tabular}

${ }^{a}$ Question number 9 not applicable.
According to the open-label clinical trials performed by Sjogren et $a l^{19}$ and by Serrano-Pozo et al, ${ }^{21}$ there were no changes in AD markers in plasma or CSF after 12 weeks of simvastatin treatment (A $\beta 40$-plasma, A $340-C S F, A \beta 42-C S F$, total tau-CSF, and phosphorylated tau-CSF). ADAs-Cog score and soluble amyloid precursor protein levels were significantly lower at the end of Sjogren et al study. ${ }^{19}$

In the latest clinical trials conducted by Sano et $\mathrm{al}^{7}$ and by Feldman et al, ${ }^{22}$ ADAS-Cog, MMSE, CGIC and NPI results were similar in statins (simvastatin and atorvastatin, respectively) and placebo patients.

Based on the outcomes of the meta-analyses included in this review, there were no differences in ADAS-Cog, MMSE, CGIC or NPI scores between placebo and treatment groups. ${ }^{23-25,27,28}$ Gizachew et al analysed four clinical trials and did not detect any variation in ADAS-Cog; ${ }^{24}$ they also included nine observational studies, one of which analysed the effect of the use of statins in MMSE without detecting any differences between treatments.

Xiong et al in their systematic review concluded that, although one study showed a slight improvement in patients treated with lovastatin versus placebo patients, the remaining trials did not show any significant differences in cognitive tests. ${ }^{29}$

\section{Discussion}

Here, we present an updated systematic review of available high-quality evidence on the efficacy of statins in $A D$ given that, over the past few years, many of the investigations published 


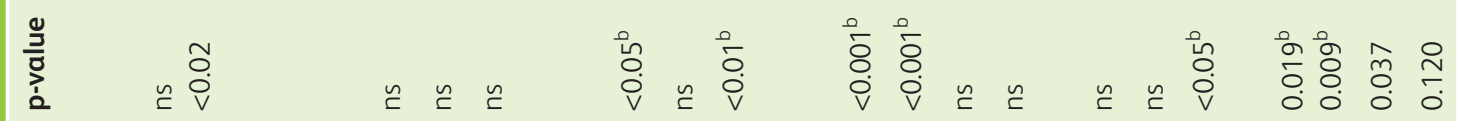

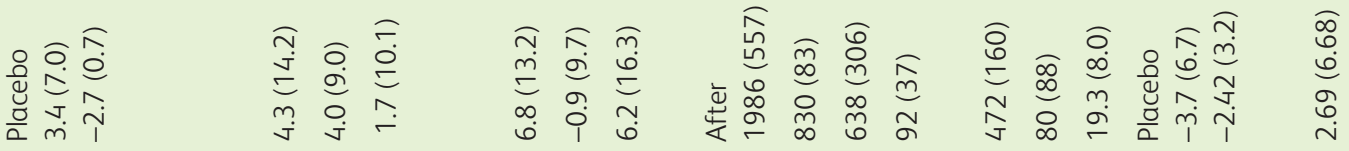

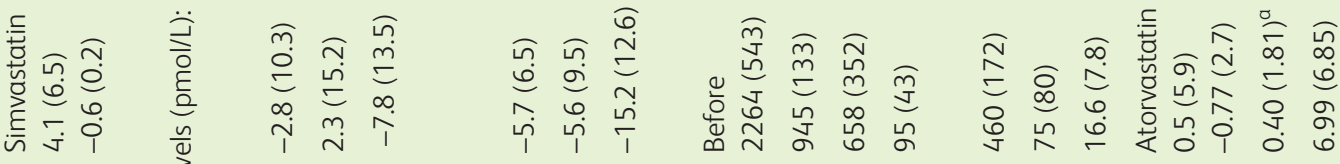

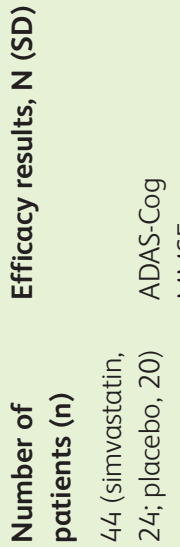

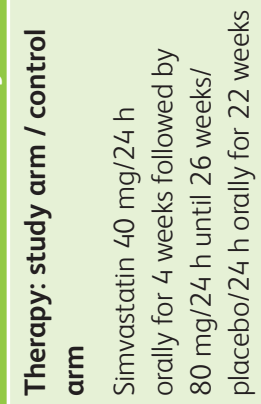

$\stackrel{9}{-}$

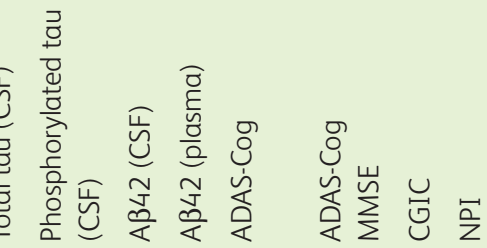

फे

$\stackrel{\circ}{n}$

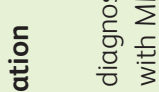

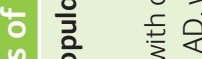

늘 $\frac{1}{2}$

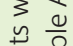

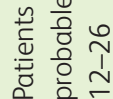
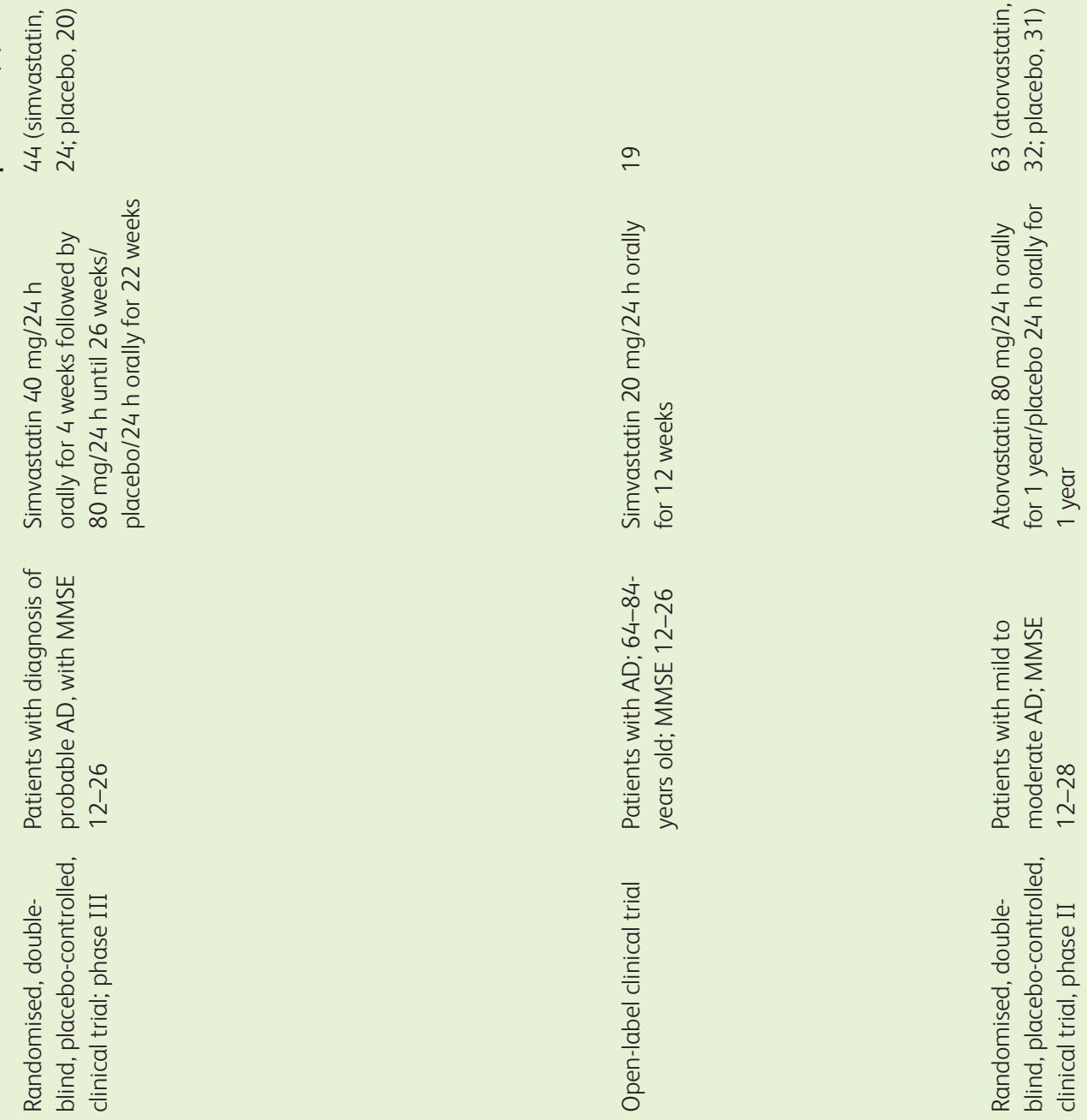

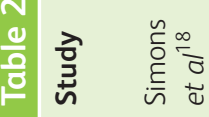

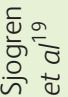

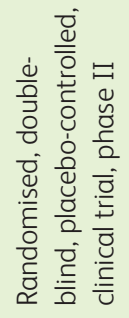

응 줄

竞皆 


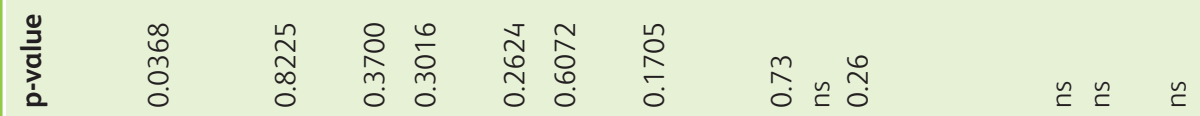

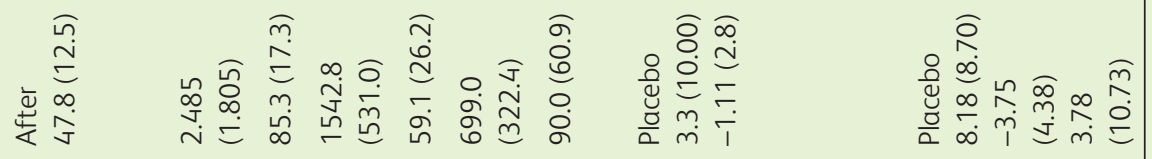

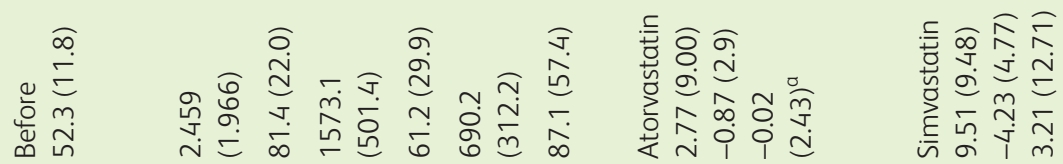

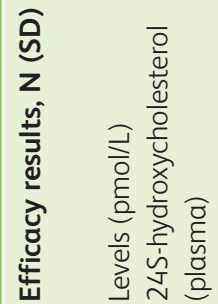

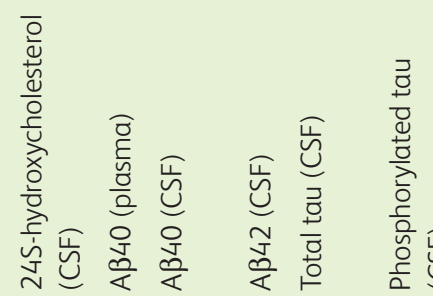

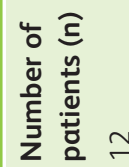

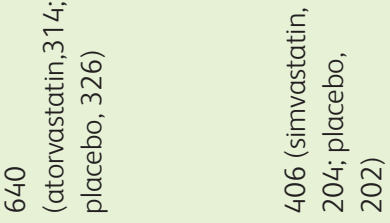

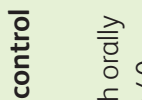

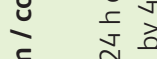

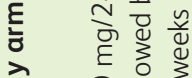

죽 일

औ

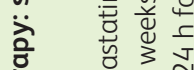

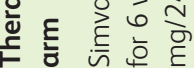

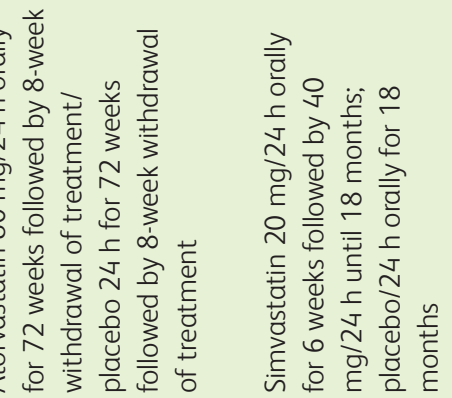

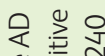

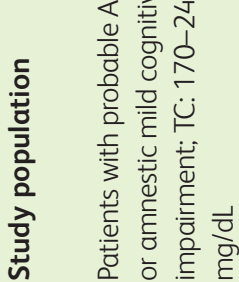

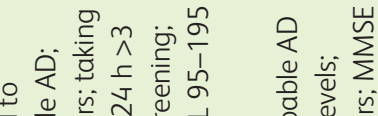

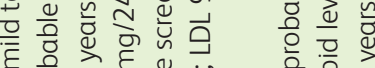

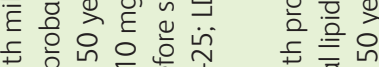

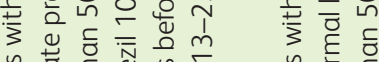

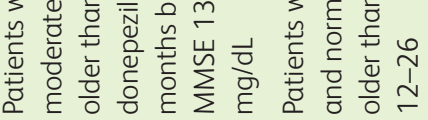

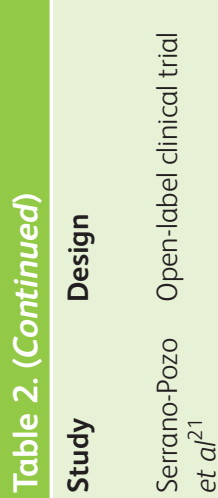
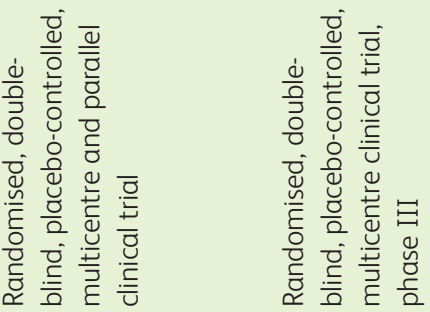

离

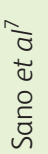

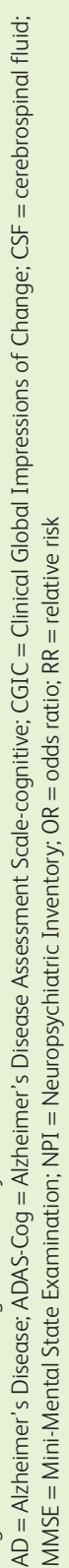


Table 3. Characteristics and efficacy results of meta-analyses included

\begin{tabular}{|c|c|c|c|c|c|}
\hline Study & Studies included & $\begin{array}{l}\text { Number of } \\
\text { patients }\end{array}$ & Selection criteria & Efficacy results; n (95\% CI) & p-value \\
\hline $\begin{array}{l}\text { Zhou } \\
\text { et al }\end{array}$ & $\begin{array}{l}\text { Two clinical trials: Simons 2002; } \\
\text { Sparks } 2005\end{array}$ & 107 & $\begin{array}{l}\text { Patients with dementia or } \mathrm{AD} \text {; } \\
\text { randomised controlled trials }\end{array}$ & ADAS-Cog: $1.84(-1.58,5.27)$ & 0.055 \\
\hline \multirow[t]{4}{*}{$\begin{array}{l}\text { Gizachew } \\
\text { et } \mathrm{al}^{24}\end{array}$} & \multirow[t]{3}{*}{ Four clinical trials } & \multirow[t]{3}{*}{1,153} & \multirow[t]{3}{*}{$\begin{array}{l}\text { Clinical trials and subjects with } \\
\text { a history or risk of } A D\end{array}$} & $\begin{array}{l}\text { ADAS-Cog: }-0.57(-1.39 \\
0.25)\end{array}$ & 0.17 \\
\hline & & & & MMSE: $0.57(-0.36,1.50)$ & 0.23 \\
\hline & & & & NPI: -0.77 (-1.59, 0.06) & 0.07 \\
\hline & Six observational studies & 21,819 & $\begin{array}{l}\text { Patients diagnosed with } A D \text { or } \\
\text { at risk for the disease }\end{array}$ & $\begin{array}{l}\text { HR: } 0.69(0.542,0.882) \\
\text { OR: } 0.447(0.229,0.668)\end{array}$ & $\begin{array}{l}0.003 \\
<0.001\end{array}$ \\
\hline Sun et $a l^{25}$ & $\begin{array}{l}\text { Two clinical trials: Sparks 2005; } \\
\text { Feldman } 2010\end{array}$ & 710 & $\begin{array}{l}\text { Patients with probable AD; } \\
\text { randomised placebo-controlled } \\
\text { clinical trials. Sparks 2005: } \\
\text { single-centre study; Feldman } \\
\text { 2010: multi-centre study }\end{array}$ & $\begin{array}{l}\text { ADAS-Cog: } 1.05(-3.06,6.05) \\
\text { MMSE: } 0.77(-0.57,2.10) \\
\text { CGIC: } 0.13(-0.15,0.40) \\
\text { NPI: } 2.07(-1.59,5.73)\end{array}$ & $\begin{array}{l}0.52 \\
0.26 \\
0.38 \\
0.27\end{array}$ \\
\hline \multirow[t]{3}{*}{$\begin{array}{l}\text { Pandey } \\
\text { et al }\end{array}$} & \multirow[t]{3}{*}{$\begin{array}{l}\text { Five clinical trials: PROSPER } \\
\text { 2002; Simons 2002; Sparks } \\
\text { 2005; Feldman 2008; Sano } 2011\end{array}$} & \multirow[t]{3}{*}{6,958} & \multirow[t]{3}{*}{$\begin{array}{l}\text { Randomised clinical trials; } \\
\text { subjects with a history or risk } \\
\text { of } A D\end{array}$} & $\begin{array}{l}\text { ADAS-Cog: }-0.18(-1.03 \\
0.66)\end{array}$ & ns \\
\hline & & & & $\begin{array}{l}\text { MMSE: }-0.921 \text { (-1.84, } \\
0.0055)\end{array}$ & $<0.05$ \\
\hline & & & & CGIC: $-0.26(-3.11,2.58)$ & ns \\
\hline \multirow[t]{4}{*}{$\begin{array}{l}\text { Richardson } \\
\text { et } a l^{27}\end{array}$} & $14 \mathrm{AD}$ studies & & $\begin{array}{l}\text { Patients; randomised controlled } \\
\text { trials }\end{array}$ & & \\
\hline & 10 cohort studies & 759,553 & Cohort study & RR: $0.79(0.63,0.99)$ & \\
\hline & Three case-control studies & 5,758 & Case-control study & OR: $0.56(0.41,0.78)$ & \\
\hline & One cross-sectional study & 57,104 & Cross-sectional study & OR: $0.45(0.35,0.58)$ & \\
\hline \multirow[t]{3}{*}{$\begin{array}{l}\text { McGuiness } \\
\text { et } a l^{28}\end{array}$} & \multirow[t]{3}{*}{$\begin{array}{l}\text { Four clinical trials: Sparks 2005; } \\
\text { Feldman 2010; Simons 2002; } \\
\text { Sano } 2011\end{array}$} & \multirow[t]{3}{*}{1154} & \multirow[t]{3}{*}{$\begin{array}{l}\text { Patients with probable AD; } \\
\text { clinical trials placebo controlled, } \\
\text { randomised, double blind }\end{array}$} & $\begin{array}{l}\text { ADAS Cog: }-0.26(-1.05 \\
0.52) \\
\text { MMSE: }-0.32(-0.71,0.06)\end{array}$ & $\begin{array}{l}0.51 \\
0.099\end{array}$ \\
\hline & & & & CGIC: $-0.02(-0.14,0.10)$ & 0.74 \\
\hline & & & & NPI: $-0.84(-1.64,-0.05)$ & 0.034 \\
\hline
\end{tabular}

$\mathrm{AD}=$ Alzheimer's disease; ADAS-Cog = Alzheimer's disease assessment scale-cognitive; $\mathrm{CGIC}=$ Clinical Global Impressions of Change; $\mathrm{CI}=$ confidence interval; $\mathrm{HR}=$ hazard ratio; $M M S E$ = mini-mental state examination; NPI = neuropsychiatric inventory; ns = non-significant; $\mathrm{OR}=$ odds ratio; $\mathrm{RR}=$ relative risk

and some clinical guidelines have included these drugs as a possible treatment option for AD. The studies included in this work highlight the limited efficacy of the use of statins in $A D$ when compared with placebo. In 2001, Friedhoff et al detected a decrease in serum $A \beta$ levels after treatment with various doses of lovastatin in patients with elevated LDL cholesterol levels but not diagnosed with $A D .^{30}$ This finding opened the way to expand research on the use of statins in AD because, by reducing the formation of atheromatous plaque, the said treatment could prevent cognitive impairment.

In 2002, Simons et al detected a small decrease in $A \beta 40$ and $A \beta 42$ levels in patients with mild-moderate $A D$ treated with simvastatin. ${ }^{18}$ However, such results were only significant in patients with milder AD. In addition, an improvement in MMSE scores was observed. For their part, Sjogren et al performed a clinical trial with one active arm treated with simvastatin, and reported a reduction in CSF levels of $\alpha$-SAPP and $\beta$-SAPP, in patients diagnosed with $A D .^{19}$ These results implied lower $\beta$-amyloid levels and, therefore, a decrease in the formation of atheromatous plaque, demonstrating that statins could interfere directly in the metabolism of secretases and in the accumulation of $A \beta$.

Likewise, in 2005, Sparks et al conducted a trial to study the efficacy of a new statin (atorvastatin calcium) versus placebo in patients with mild-moderate AD. ${ }^{20}$ This study measured ADAS-Cog, MMSE, CGIC and NPI scores, detecting differences between both treatment arms in the first three efficacy variables. Subsequently, the authors performed a post hoc analysis that showed that the efficacy of atorvastatin calcium was closely related to baseline cholesterol levels and to the apoE genotype. ${ }^{31}$ Hence, patients with high cholesterol levels and those who are carriers of the apoE $\varepsilon 4$ allele would be more likely to benefit from the use of statins early in their treatment. However, the limitations of this type of post hoc study make it difficult to generalise these findings. ${ }^{14}$

In 2010 and 2011, two clinical trials with larger sample sizes were carried out. Feldman et al studied the efficacy of atorvastatin in 
patients with medium-moderate $A D$, detecting no significant differences between treatment and placebo groups in ADAS-Cog, MMSE and CGIC scores. ${ }^{22}$ Later, Sano et al did not observe any cognitive improvement in ADAS-Cog and MMSE scores in patients with mild-moderate AD after treatment with simvastatin. ${ }^{7}$ Although they identified a reduction in cholesterol levels in the statin treatment arm, their findings did not support the use of these drugs in AD.

After analysing the articles selected, we suggest that statins have not been proven to be of clear benefit for the treatment of $A D$. This claim relies on the fact that the main variables of the disease measured have not shown a significant improvement in patients treated with statins, compared with those who were administered a placebo.

Our review reinforces the findings of previous studies and meta-analyses carried out by Zhou et al, ${ }^{23}$ Gizachew et $a l^{24}$ and Richardson et $a{ }^{27}{ }^{27}$ in which the main variables indicating cognitive impairment indicated negative results on the use of statins for the treatment of AD. The results of our review are supported by our inclusion of more, high-quality, articles compared with these previous reports.

Also, Miller et al performed a narrative review in which they included clinical trials investigating the use of statins and AD. ${ }^{32}$ According to their study, evidence suggested that these drugs could offer a protective effect against the development of AD and had been proven to be useful as long-term therapy for hyperlipidaemia. However, the authors concluded that available studies assessing the use of statins had numerous confusing variables possibly skewing results and, therefore, they might not provide suitable clinical evidence as to whether these agents have an effect on the progression of AD. Hence, the authors did not recommend the use of statins as prophylaxis in patients with $A D$ without hyperlipidaemia.

Additionally, patients diagnosed with AD are usually older and most have multimorbidities, frequently treated with polypharmacy. ${ }^{33}$ It is essential to apply measures to reduce the number of drugs in these patients, with the purpose of preventing adverse reactions, improving adherence and reducing costs. Indeed, it is necessary to deprescribe drugs whose risk-benefit balance is controversial. ${ }^{34}$ Given the efficacy demonstrated by statins for the treatment of $A D$, these drugs can be considered as susceptible to this process.

Among the limitations of our review is the delay between the date when the article search was finished (April 2016) and the date of its publication, which resulted from the high number of studies that were reviewed. Also, we have only considered studies that analyse the use of statins as treatment for $A D$ and did not include those that analysed these drugs as prophylaxis against the disease. However, other systematic reviews on this topic have been recently published and, therefore, in this case, it would be difficult to provide relevant evidence in this regard.

Nevertheless, the present study includes updated information with a high level of evidence on the poor efficacy of the use of statins for the treatment of AD.

\section{Conclusions}

Although some previous studies suggest that the use of statins could offer a protective effect against AD, according to available evidence, the studies examined here do not provide enough evidence and do not show conclusive results that support the efficacy of statins for the treatment of AD. Therefore, the use of statins as treatment for this disease should not be recommended.

\section{Author contributions}

MM-T, MAP-M and MAF-A contributed to the design of the study; MM-T and MAP-M realised the acquisition and analysis of data, the peer-review process and the drafting of the manuscript; MM-T, MAP-M and MAF-A revised the manuscript critically for intellectual content and approved the final version to be submitted; MAP-M submitted the manuscript.

\section{Acknowledgements}

We would like to thank the Department of Pharmacy of University Hospital Virgen del Rocío and the Faculty of Pharmacy of the University of Seville, Spain.

\section{References}

1 Alzheimer's Disease International, 2015; Dementia statistics. www. alz.co.uk/research/statistics [Accessed 2 December 2017].

2 Medline Plus. National Library of USA. 2017. https://medlineplus. gov/ency/article/000760.htm [Accessed 2 December 2017].

3 Dickson DW. Neuropathological diagnosis of Alzheimer's disease: a perspective from longitudinal clinicopathological studies. Neurobiol Aging 1997;18:S21-6.

4 Haass $C$, Selkoe DJ. Cellular processing of $\beta$-amyloid precursor protein and the genesis of amyloid $\beta$-peptide. Cell 1993;75:103942.

5 Wolozin B. A fluid connection: cholesterol and Abeta. Proc Natl Acad Sci USA 2001;98:5371-3.

6 Simons M, Keller P, De Strooper B et al. Cholesterol depletion inhibits the generation of beta amyloid in hippocampal neurons. Proc Natl Acad Sci USA 1998;95:6460-4.

7 Sano M, Bell KL, Galasko D et al. A randomized, double-blind, placebo-controlled trial of simvastatin to treat Alzheimer disease. Neurology 2011;77:556-63.

8 Bright Focus Foundation, cure in mind, cure in sight, 2017. https:// www.brightfocus.org/file/brightfocus-foundation-cure-mind-curesight-2017 [Accessed 2 December 2017].

9 Summary of Product Characteristics (Simvastatin). European Medicines Agency, 2017. www.ema.europa.eu/ema/ [Accessed 2 December 2017].

10 Jick H, Zornberg GL, Jick SS, Seshadri S, Drachman DA. Statins and the risk of dementia. Lancet 2000;356:1627-31.

11 Wolozin B, Kellman W, Ruosseau, Celesia GG, Siegel G. Decreased prevalence of Alzheimer disease associated with 3-hydroxy3-methyglutaryl coenzyme A reductase inhibitors. Arch Neurol 2000;54:1439-43.

12 Fassbender K, Simons M, Bergmann C et al. Simvastatin strongly reduces levels of Alzheimer's disease beta-amyloid peptides Abeta 42 and Abeta 40 in vitro and in vivo. Proc Natl Acad Sci USA 2001:98:5856-61.

13 CPG Development Group on the comprehensive care of people with Alzheimer's disease and other dementias. Clinical Practice Guideline on the comprehensive care of people with Alzheimer's disease and other dementias. Quality Plan for the National Health System of the Ministry of Health, Social Policies and Equality. Catalonia: Agència d'Informació, Avaluació i Qualitat en Salut of Catalonia, 2010

14 Geifman N, Brinton RD, Kennedy RE, Schneider LS, Butte AJ. Evidence for benefit of statins to modify cognitive decline and risk in Alzheimer's disease. Alzheimers Res Ther 2017;9:10.

15 Liberati A, Altman DG, Tetzlaff ] et al. The PRISMA statement for reporting systematic reviews and meta-analyses of studies that evaluate health care interventions: explanation and elaboration. Ann Intern Med 2009;151:W65-94.

16 Instruments for critical reading. Systematic review tool. Critical Appraisal Skills Program, 2016. www.redcaspe.org/herramientas/ instrumentos [Accessed 4 December 2017]. 
17 Shea B], Grimshaw JM, Wells GA et al. Development of AMSTAR: a measurement tool to assess the methodological quality of systematic reviews. BMC Med Res Methodol 2007;7:10.

18 Simons M, Schwarzler F, Lutjohann D et al. Treatment with simvastatin in normocholesterolemic patients with Alzheimer's Disease: a 26-week randomized, placebo-controlled, double-blind trial. Ann Neurol 2002:52:346-50.

19 Sjogren M, Gustafsson K, Syversen S et al. Treatment with simvastatin in patients with Alzheimer's disease lowers both $\alpha$ - and $\beta$-cleaved amyloid precursor protein. Dement Geriatr Cogn 2003;16:25-30.

20 Sparks D, Sabbagh M, Connor D et al. Atorvastatin therapy lowers circulating cholesterol but not free-radical activity in advance of identifiable clinical benefit for the treatment of mild-to-moderate AD. Curr Alzheimer Res 2005;2:343-53.

21 Serrano-Pozo A, Vega GL, Lutjohann D et al. Effects of simvastatin on cholesterol metabolism and Alzheimer disease biomarkers. Alzheimer Dis Assoc Disord 2010;24:220-6.

22 Feldman HH, Doody RS, Kivipelto $M$ et al. Randomized controlled trial of atorvastatin in mild to moderate Alzheimer disease: LEADe. Neurology 2010;74:956-64.

23 Zhou B, Teramukai S, Fukushima M. Prevention and treatment of dementia or Alzheimer's disease by statins: a meta-analysis. Dementia and Geriatric Cognitive Disorders 2007;23:194-201.

24 Gizachew S, Makonnen E. The role of statins in Alzheimer's disease: a meta-analysis. Afr J Neurol Sci 2012;2:2002-12.

25 Sun Y, Wang G, Pan Z, Chen S. Systematic review of atorvastatin for the treatment of Alzheimer's disease. Neural Regen Res 2012;7:1344-51

26 Pandey RD, Gupta PP, Jha D, Kumar S. Role of statins in Alzheimer's disease: a retrospective meta-analysis for commonly investigated clinical parameters in RCTs. Int J Neurosci 2013;123:521-5.
27 Richardson K, Schoen M, French B et al. Statins and cognitive function. Ann Intern Med 2013;159:688-97.

28 McGuinness B, Craig D, Bullock R, Malouf R, Passmore P. Statins for the treatment of dementia. Cochrane Database Syst Rev 2010; CD007514.

29 Xiong G, Benson A, Murali P. Statins and cognition: what can we learn from existing randomized trials? CNS Spectr 2005;10:867-74.

30 Friedhoff LT, Cullen EI, Geoghagen NSM, Buxbaum JD. Treatment with controlled-release lovastatin decreases serum concentrations of human $\beta$-amyloid ( $A \beta$ ) peptide. Int J Neuropsychoph 2001:4:127-30.

31 Sparks DL, Connor DJ, Sabbagh MN et al. Circulating cholesterol levels, apolipoprotein E genotype and dementia severity influence the benefit of atorvastatin treatment in Alzheimer's disease: results of the Alzheimer's Disease Cholesterol-Lowering Treatment (ADCLT) trial. Acta Neurol Scand 2006;114:3-7.

32 Miller LJ, Chacko R. The role of cholesterol and statins in Alzheimer's disease. Ann Pharmacother 2004;38:91-8.

33 Franchi C, Cartabia M, Risso P. Geographical differences in the prevalence of chronic polypharmacy in older people: eleven years of the EPIFARM elderly project. Eur J Clin Pharmacol 2013;69:147783.

34 Rodríguez Pérez A, Alfaro Lara ER, Nieto Martín MD, Ruiz Cantero A, Santos Ramos B. Deprescribing in patients with multimorbidity: a necessary process. Eur J Intern Med 2015;26:e18-9.

Address for correspondence: Maria Antonia Pérez Moreno, Pharmacy Department, University Hospital Virgen del Rocio. Av. Manuel Siurot s/n, 41013, Seville, Spain.

Email: sg.pm.mary@gmail.com 